\title{
ОБРАТНЫЕ ЭМУЛЬСИИ, СТАБИЛИЗИРОВАННЫЕ МОНОЭТАНОЛАМИДАМИ ЖИРНЫХ КИСЛОТ ПОДСОЛНЕЧНОГО МАСЛА
}

\author{
(C) 2017 К. В. Илюшина, А. С. Шестаков, М. А. Кузьминова, А. В. Фалалеев \\ Воронежский государственный университет, Университетская пл., 1, 394018 Воронеж, Россия \\ e-mail: ilyushina.ksyu@yandex.ru
}

Поступила в редакцию 14.09.2017

\begin{abstract}
Аннотация. Получены моноэтаноламиды жирных кислот подсолнечного масла, разработан способ разделения моноэтаноламидов насыщенных и ненасыщенных жирных кислот. С использованием фракции ненасыщенных жирных кислот получены обратные эмульсии на основе дизельного топлива и подсолнечного масла. Изучена стабильность обратных эмульсий в зависимости от объемов фаз, концентрации эмульгатора и природы гидрофобной фазы.
\end{abstract}

Ключевые слова: моноэтаноламиды, жирные кислоты, подсолнечное масло, обратные эмульсии, эмульгаторы.

\section{ВВЕДЕНИЕ}

Моноэтаноламиды - это неионогенные ПАВ, которые являются продуктами реакций амидирования жирных кислот, эфиров жирных кислот, в том числе триглицеридов, моноэтаноламином (МЭА).

Поверхностно-активные вещества на основе биологических компонентов - жирных кислот, натуральных жиров и масел, имеют большое значение в различных областях промышленности. Алкилоламиды используются в качестве пеноусилителей, пеностабилизаторов и вязких структурообразователей. Также они проявляют свойства детергентов, смачивателей и эмульгаторов [1]. Нейтрализация, этерификация, амидирование, этоксилирование или конденсация жирных кислот, полученных путем расщепления жиров и масел позволяют получить соответствующие ПАВ или эмульгаторы [2].

Одним из наиболее важных направлений использования моноэтаноламидов является использование их в качестве эмульгаторов обратных эмульсий. В настоящее время в России среди эмульгаторов обратных эмульсий распространены как зарубежные реагенты, широко представленные на рынке, так и отечественные разработки [1]. В качестве эмульгаторов обратных эмульсий используются неионогенные ПАВ, хорошо растворимые в углеводородах: синтетические жирные кислоты $\left(\mathrm{C}_{17}-\mathrm{C}_{24}\right)$, эфиры триэтаноламина и кислот таллового масла (эмультал), окисленные тяжелые нефтяные углево- дороды (окисленный петролатум, высокоокисленный битум), алкилоламиды жирных кислот, оксиэтилалкил-имидазолины, полиизобутиленянтарный ангидрид и др.

Учитывая постоянно ужесточающиеся требования к технологическим характеристикам обратных эмульсий, разработка принципиально новых и качественное улучшение свойств уже существующих эмульгаторов являются весьма актуальной научнотехнической задачей. На наш взгляд, одним из перспективных направлений в этой области является совершенствование методов получения эмульгаторов на основе растительных масел и этаноламина. В связи с этим целью исследования явилась разработка методов синтеза моноэтаноламидов жирных кислот подсолнечного масла, анализ состава полученных ПАВ, получение обратных эмульсий на основе дизельного топлива и подсолнечного масла и изучение их стабильности.

\section{ЭКСПЕРИМЕНТАЛЬНАЯ ЧАСТЬ}

\section{Синтез моноэтаноламидов жирных кислот подсолнечного масла}

0.08 г (3.5 ммоль) металлического натрия при нагревании вносили в 15.5 мл (0.7 моль) моноэтаноламина и перемешивали до полного растворения. Полученный раствор катализатора в этаноламине смешивали с 55 г (0.195 моль) подсолнечного масла. Смесь нагревали $\left(90-100{ }^{\circ} \mathrm{C}\right)$ при постоянном перемешивании в течение 30 мин до 
полной гомогенизации. К полученному раствору добавляли пятикратный объем дистиллированной воды, смесь подкисляли ледяной уксусной кислотой до рН 6, отделяли водный слой и органическую фазу трижды промывали дистиллированной водой.

Для выделения моноэтаноламидов из эмульсии использовали метод центрифугирования. По 5 мл полученной смеси помещали в пробирки и центрифугировали их в течение 5 мин со скоростью 15000 об/мин на центрифуге MPV-310. В результате смесь разделялась на три слоя. Отделяли верхние желтый и белый слои, водный слой отбрасывали. Выход моноэтаноламидов жирных кислот подсолнечного масла составил $65 \%$.

\section{Анализ полученных веществ}

Хроматографический анализ полученных соединений осуществляли на хроматографе Agilent7890B с масс-детектированием. Пробоподготовку к хроматографированию осуществляли следующим образом. Обезвоженный образец, в количестве 9.8 мг, растворяли в 1.0 мл абс. пиридина и силилировали 200 мкл N,O-бис(триметилсил ил)трифторацетамида с $1 \%$ триметилхлорсилана в течение 30 мин при $75^{\circ} \mathrm{C}$. Затем 100 мкл аналита растворяли в 1.0 мл хлористого метилена. Разделение проводили на неполярной колонке HP $5 \mathrm{msUI}$, 30 м, газ-носитель - гелий (1.5 мл/мин); инжекция 1 мкл; инжектор $300{ }^{\circ} \mathrm{C}$; термостат $220^{\circ} \mathrm{C}$ (4 мин) до 270 (3 К/мин). В качестве детектора масс использовали времяпролетный детектор Agilent5977А. Ионизация - электронный удар (70 эВ).

\section{Методика получения обратных (прямых) эмульсий}

С помощью пипетки вносили в коническую колбу определенный объем (5-40 мл) углеводородной фазы - дизельного топлива (подсолнечного масла). Далее пипеткой при перемешивании вносили расчетное количество эмульгатора. Необходимый объем (60-95 мл) дистиллированной воды отмеряли мерным цилиндром. Эмульгирование с помощью мешалки IKA Eurostar 40 digital проводили при частоте вращения вала 700 об/мин в течение 10 мин. Водную фазу добавляли постепенно. Ультразвуковое эмульгирование проводили с помощью генератора УЗГ13-0.1/22, с частотой 22 кГц в течение 10 мин. Водную фазу также добавляли постепенно. Оба эксперимента проводились при температуре окружающей среды $\left(20-23{ }^{\circ} \mathrm{C}\right)$. Содержимое колб переливали в цилиндры и оставляли для дальнейшего наблюдения.

\section{Методика определения типа эмульсии и микроскопические исследования}

1. Метод разбавления. Каплю, эмульсии помещали в стакан с водой и тщательно перемешивали. Разрушение капли свидетельствовало о том, что это эмульсия прямого типа, сохранение капли - обратного.

2. Метод электропроводности. Значения электропроводности измеряли на «Учебно-лабораторном комплексе «Химия»»». Прямые эмульсии, в отличие от обратных, лучше проводят электрический ток [3]. На основании показаний кондуктометра, делали вывод о типе эмульсии.

3. Метод окраски. Небольшое количество жирорастворимого красителя Судан I вносили в обе эмульсии. Эмульсия, приготовленная с использованием ультразвукового генератора, не окрашивалась, в отличие от эмульсии, приготовленной на механической мешалке, которая окрашивалась в ярко-оранжевый цвет. Окрашенную эмульсию рассматривали под микроскопом.

Исследования выполняли на микроскопе PrimoStar (CarlZeiss, Iena), увеличение $40 \times 1.5 \times 10$ и $100 \times 1.5 \times 10$.

\section{Методика определения устойчивости эмульсии}

Цилиндры с приготовленными эмульсиями накрывали крышками и оставляли при комнатной температуре. Момент разрушения эмульсии определяли визуально. Стабильность эмульсии определяли по-разному. В эмульсиях, где углеводородной фазой было подсолнечное масло, оценивали время, прошедшее с момента приготовления эмульсии до момента ее разрушения. В эмульсиях с дизельным топливом оценивали стабильность по времени выделения углеводородной фазы с момента ее приготовления до момента появления масляных пятен на поверхности эмульсии.

\section{ОБСУЖДЕНИЕ РЕЗУЛЬТАТОВ}

Синтез моноэтаноламидов с использованием растительных масел и моноэтаноламина является экономически наиболее целесообразным, однако для успешного осуществления процесса необходимо решение ряда проблем.

Процесс протекает в условиях основного катализа. Достаточно часто в качестве катализатора используют $\mathrm{NaOH}$ или $\mathrm{KOH}[4,5,6]$, однако реакция в этом случае протекает при высоких температурах с образованием побочных продуктов и выделением воды, которую необхо- 
димо удалять из зоны реакции. Без выделения воды реакция протекает в присутствии метилата натрия [7, 8, 9].

Мы проводили конденсацию по разработанной нами ранее методике [10] в присутствии $1.8 \%$ аминоэтилата натрия, который получали непосредственно перед процессом. Реакция протекает достаточно энергично и заканчивается в течение 30-40 мин. Реакционная масса содержит выделившийся глицерин, избыток моноэтаноламина и примеси солей натрия. При охлаждении такая масса затвердевает, так как содержит высокоплавкие (86 и $103{ }^{\circ} \mathrm{C}$ соответственно [10]) моноэтаноламиды пальмитиновой и стеариновой кислот и алкоголяты натрия. Полученная таким образом смесь может быть использована в качестве эмульгатора [10], однако использование твердого эмульгатора не технологично. Для дальнейшего изучения проводили очистку моноэтаноламидов жирных кислот.

Известны традиционные методы, заключающиеся в использовании двухфазной системы на основе гидрофобных растворителей и водных растворов $[11,12,13]$. Мы использовали водную отмывку не успевшей затвердеть реакционной массы от гидрофильных компонентов. Для этого добавляли пятикратный объем воды, после энергичного перемешивания подкисляли уксусной кислотой до нейтральных значений $\mathrm{pH}$, отделяли водную фазу и дважды повторяли отмывку дистиллированной водой. В результате получена вязкая жидкая фаза, не поддающаяся фильтрованию.
Для отделения фракции моноэтаноламидов от воды мы использовали центрифугирование. Ранее такой прием был использован для извлечения алкилоламидов на основе жирных кислот микроводорослей [12], однако для разделения фаз использовался этилацетат, т.е. по сути, проводилась экстракция. При центрифугировании происходило разделение вязкой жидкой фазы на три слоя: нижний прозрачный водный, верхний желтый и белую промежуточную фазу.

Две верхние органические фазы анализировали методом газовой хроматографии с масс-спектрометрическим детектированием (рис. 1). Для оптимизации процесса хроматографирования проводили силилирование алкилоламидов, что является стандартной процедурой при подобного рода исследованиях $[12,14,15,16]$. В результате время хроматографирования не превышало 15 мин при постепенном повышении температуры от 220 до $270{ }^{\circ} \mathrm{C}$ при скорости тока гелия 1.5 мл/мин.

Как оказалось, две органические фазы, полученные в результате центрифугирования, различаются жирнокислотным составом. В верхнем желтом слое практически отсутствуют моноэтаноламиды насыщенных пальмитиновой и стеариновой кислот и содержатся только моноэтаноламиды линолевой и олеиновой кислот. В среднем белом слое содержатся моноэтаноламиды всех жирных кислот входящих в состав триглицеридов подсолнечного масла, однако содержание моноэтаноламидов пальмитиновой и стеариновой кислот составляет при-

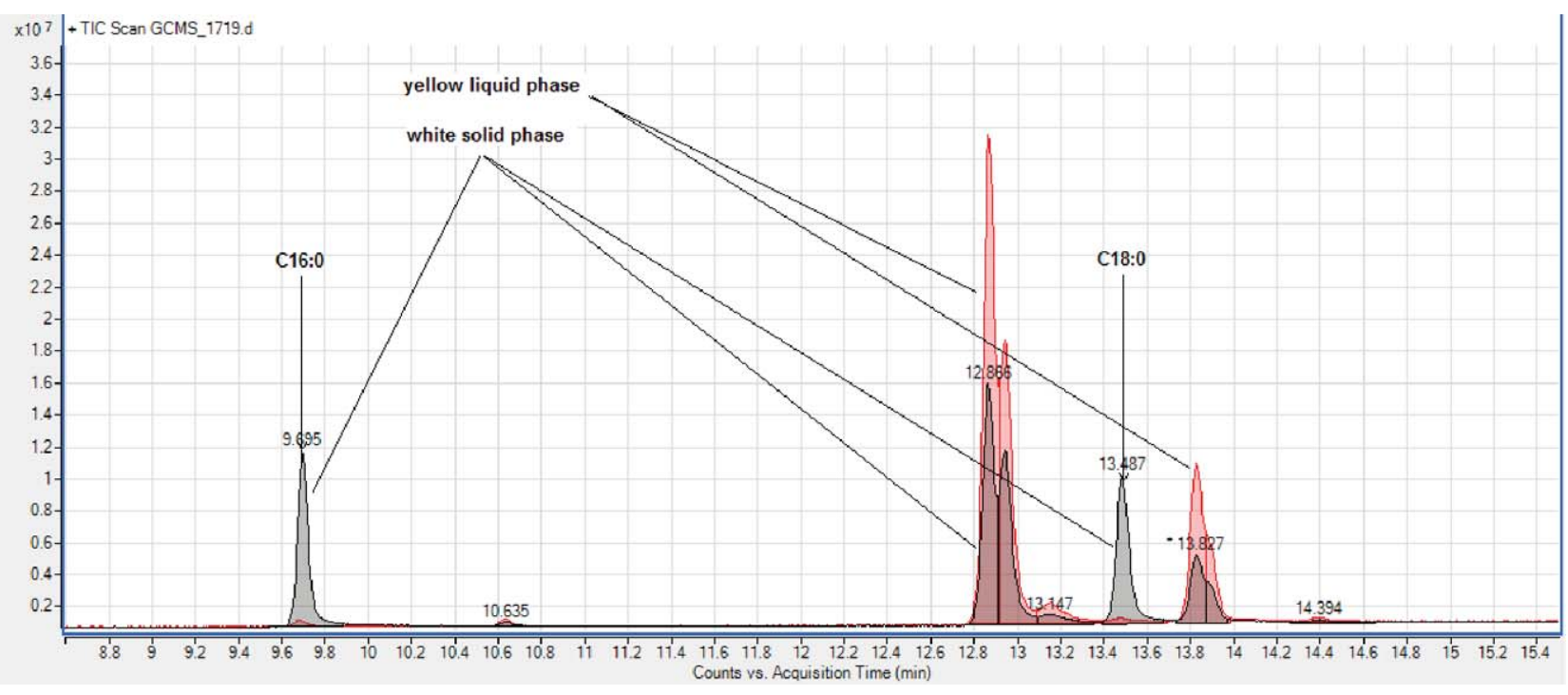

Рис. 1. Данные ВЭГХ-МС органических фаз, полученных в результате центрифугирования

[Fig. 1. HPGC-MS data of organic phases obtained as a result of centrifugation] 
мерно $36 \%$, что существенно больше их содержания в исходных триглицеридах подсолнечного масла (5-9 \%). Наряду с моноэтаноламидами в обеих фазах присутствуют моноглицериды жирных кислот, остающиеся после амидирования триглицеридов. В дальнейшем в качестве эмульгатора использовали фазу не содержащую моноэтаноламидов насыщенных жирных кислот.

Известны различные методы получения эмульсий. Это методы прерывистого встряхивания, смешения, методы с использованием коллоидных мельниц и гомогенизаторов [3]. В последнее время активно внедряются методы с использованием ультразвуковой техники. Мы использовали метод диспергирования с использованием высокоскоростной мешалки и метод с использованием ультразвукового облучателя. Неполярной фазой являлось соляровое масло.

В обоих случаях объем водной фазы в процессе эмульгирования увеличивали постепенно, однако внешне эмульсии, полученные этими методами, различались. Эмульсия, полученная ультразвуковой обработкой, представляла ярко-белую подвижную жидкость. Эмульсия, полученная при перемешивании, представляла матово-белую густую и вязкую жидкость. Для определения типа полученных эмульсий использовали ряд методов.

Наиболее простым и наглядным является метод разбавления, заключающийся в том, что в воду добавляют каплю эмульсии. При добавлении капли эмульсии, полученной ультразвуковой обработкой, она равномерно распределяется во всем объеме, что свидетельствует о том, что это эмульсия типа М/В. При добавлении капли эмульсии, полученной с использованием мешалки, она не диспергировалась и сохраняла свою форму, на основании чего можно утверждать, что эмульсия типа В/M.

Выводы подтвердились измерением электропроводности полученных эмульсий. Так электропроводность эмульсии, полученной ультразвуковой обработкой $\left(æ_{\text {узг }}=0.04 \cdot 10^{-3} \mathrm{CM}^{\cdot} \mathrm{cm}^{-1}\right)$, на порядок превышала электропроводность эмульсии, полученной с использованием мешалки $\left(æ_{\text {меш }}=0.004 \cdot 10^{-3} \mathrm{CM}^{\cdot} \mathrm{cm}^{-1}\right)$. Действительно, водная непрерывная фаза обладает намного большей электропроводностью, чем масляная, поэтому эмульсия $\mathrm{M} / \mathrm{B}$ лучше проводит электрический ток.

Наконец исследования эмульсий с использованием микроскопа также свидетельствовали о том, что эмульсия, полученная при перемешивании, является эмульсией типа В/М. При добавлении жирорастворимого красителя Судан I эмуль- сия, полученная при перемешивании, окрашивалась в оранжевый цвет, причем под микроскопом отчетливо видны окрашенная дисперсионная среда и бесцветные шарики дисперсной фазы. Для эмульсии, полученной с использованием ультразвука, такой картины не наблюдалось. Использование микроскопа с увеличением 100 позволило определить размер частиц обратной эмульсии. Он составил 2-10 мкм.

Основными направлениями использования обратных эмульсий в настоящее время являются приготовление буровых растворов и создание эмульсионных взрывчатых веществ. В обоих случаях неполярной фазой являются жидкие углеводороды. Для получения обратных эмульсий мы использовали дизельное топливо.

Как оказалось, разрушение обратных эмульсий на основе солярового масла с использованием фракции, содержащей моноэтаноламиды ненасыщенных жирных кислот в качестве эмульгатора протекает в две стадии. На первой стадии происходит отделение части масла с образованием верхнего органического слоя и нижнего слоя стабильной эмульсии. Отделение происходит в течение первых трех суток после эмульгирования. После разделения объем образовавшихся фаз не изменялся, и далее в течение нескольких недель происходило разрушение эмульсии. Мы проследили зависимость первой стадии разрушения эмульсии от объема углеводородной фазы. Как видно из данных, представленных на рис. 2, медленнее всего происходит отделение масляного слоя в том случае, когда объем солярового масла при получении эмульсии составляет 12-17 мл (12-17 \%).

Рассмотренная выше зависимость была получена при содержании 1 \% (масс) эмульгатора. Мы проследили, как меняется время отделения масла на первой стадии от концентрации эмульгатора. Объем углеводородной фазы в этом случае составлял 20 мл. Как и можно было ожидать, стабильность эмульсии на первой стадии разрушения напрямую зависит от концентрации эмульгатора (рис. 3).

В косметике обратные эмульсии получают на основе природных масел, поэтому представляла интерес стабильность этих коллоидных систем на основе подсолнечного масла. Как оказалось, характер разрушения эмульсии в этом случае совершенно иной. При использовании тех же соотношений углеводородной фазы и воды, что и ранее, не удавалось получить устойчивую эмульсию во всем объеме. Сразу происходило отделение нижнего водно- 


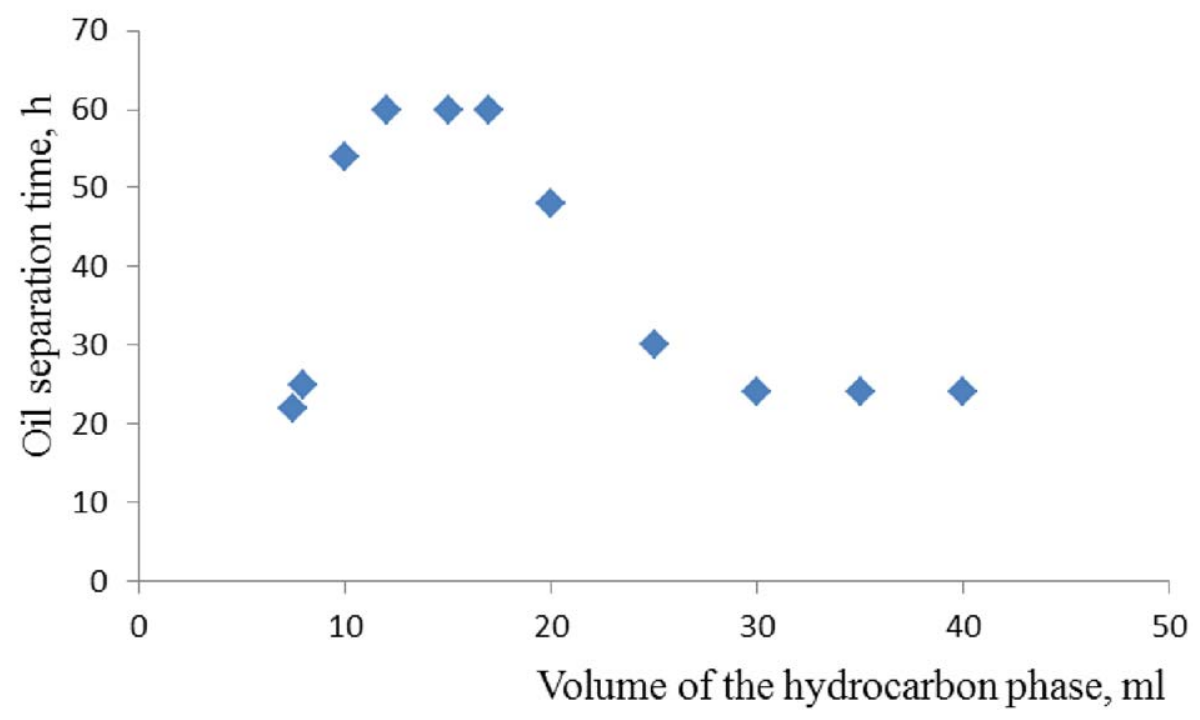

Рис. 2. Зависимость стабильности эмульсии от объема углеводородной фазы. Углеводородная фаза - дизельное топливо, концентрация эмульгатора 1 \% (масс)

[Fig. 2. Dependence of emulsion stability on the volume of the hydrocarbon phase. Hydrocarbon phase - diesel fuel, concentration of emulsifier $1 \%$ (mass)]

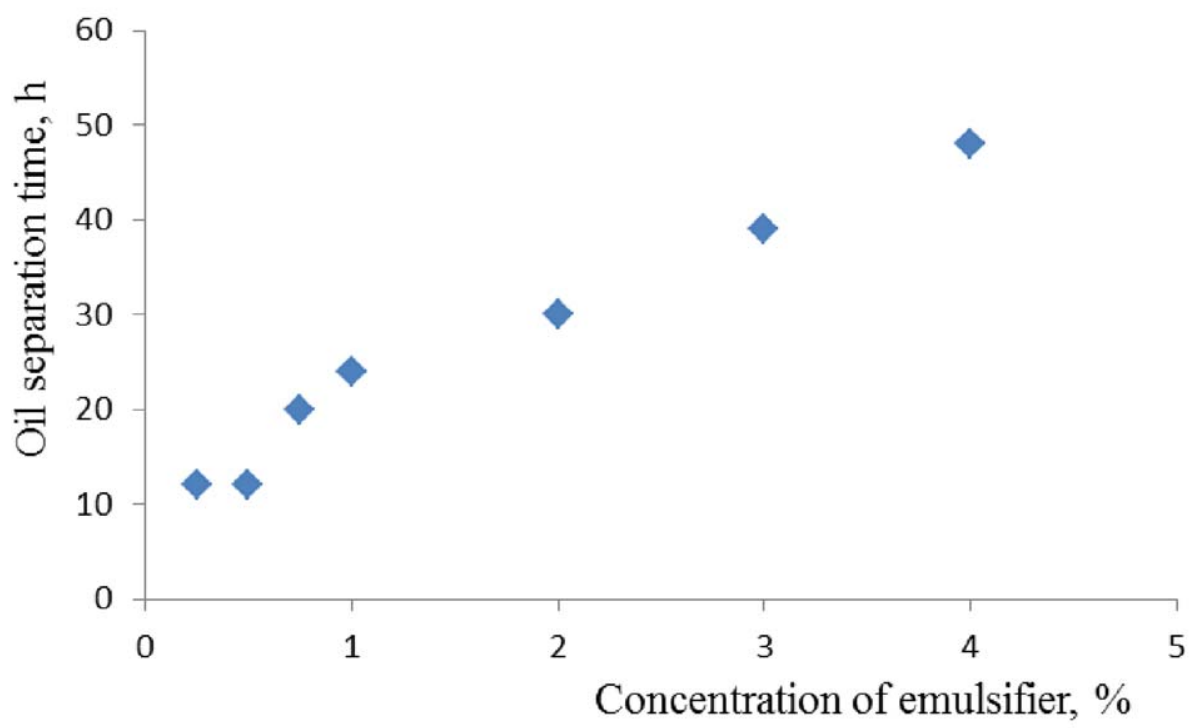

Рис. 3. Зависимость стабильности эмульсии от концентрации эмульгатора. Углеводородная фаза - дизельное топливо (20 мл)

[Fig. 3. Dependence of emulsion stability on emulsifier concentration. The hydrocarbon phase is diesel fuel $(20 \mathrm{ml})]$

го слоя и верхнего слоя эмульсии. Объем верхнего слоя линейно зависел от объема масла, используемого при получении эмульсии (рис. 4).

В дальнейшем полученная эмульсия разрушалась в течение трех суток с образованием прозрачных слоев подсолнечного масла и воды. Зависимость времени расслоения от концентрации эмульгатора представлена на рис. 5.
Таким образом, эмульсии на основе подсолнечного масла гораздо менее стабильны. Если в случае дизельного топлива можно получить обратные эмульсии с соотношением фаз вода: масло 9:1, то в случае подсолнечного масла образуются нестабильные обратные эмульсии с преобладанием масляной фазы. 


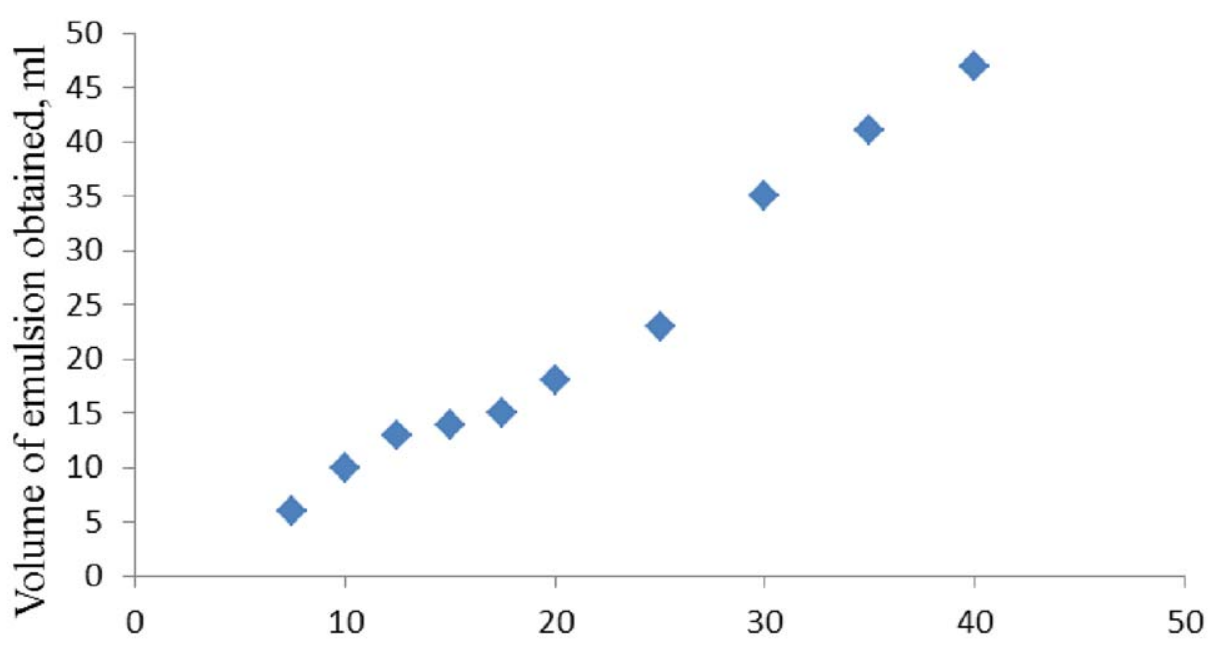

Volume of the hydrocarbon phase, $\mathrm{ml}$

Рис. 5. Зависимость стабильности эмульсии от концентрации эмульгатора. Углеводородная фаза - подсолнечное масло (20 мл)

[Fig. 5. Dependence of emulsion stability on emulsifier concentration. Hydrocarbon phase - sunflower oil $(20 \mathrm{ml})]$

\section{ЗАКЛЮЧЕНИЕ}

В результате проведенного исследования был разработан способ получения моноэтаноламидов жирных кислот подсолнечного масла отличающийся тем, что в качестве катализатора используется аминоэтилат натрия и целевой продукт выделяется центрифугированием. Методом центрифугирования возможно получение фракции моноэтаноламидов не содержащей производных пальмитиновой и стеариновой кислот. Установлено, что тип эмульсии на основе дизельного топлива и воды зависит от способа получения: в результате ультразвуковой обработки образуется эмульсия масло/вода, в то время как использование высокоскоростной мешалки приводит к образованию эмульсии вода/масло. Характер разрушения эмульсии зависит от природы неполярной фазы: эмульсии на основе дизельного топлива более стабильны и процесс их разрушения включает две стадии первой из которых является отделение части масляной фазы, в то время как эмульсии на основе подсолнечного масла менее стабильны и разрушаются по одностадийному механизму.

\section{СПИСОК ЛИТЕРАТУРЫ}

1. Lange K. R. Surfactants: a Practical Handbook. Hanser Publishers, Munich, 1999.

2. Maag H. // J. Am. Oil. Chem. Soc., 1984, vol. 61, № 2, p. 259.
3. Sherman Ph. Emulsion Science. Academic Press. London and New York, 1968.

4. Lauermann H. Patent GDR, № 209190, 1984.

5. Чебаксарова Л. В., Худолеева Е. С., Гурбанова Л. В. Патент РФ № 24516666, 2012.

6. Карпеева И. В., Зорина А. В., Шихалиев Х. С. // Вестник ВГУ. Серия: химия, биология, фармация, 2013, № 2, c. 39-41.

7. Kolancilar H. // J. Amer. Oil. Chem. Soc., 2004, vol. 81, № 6, p. 597.

8. Dzylkefly D. // J. Oil Palm Res., 1997, vol. 9, № 2, p. 61.

9. Wang X., Han Z., Chen Y., Jin Q., Wang. X. // J. Am. Oil. Chem. Soc., 2016, vol. 93, № 1, p. 125.

10. Черных Е. И., Шестаков А. С., Пояркова Т. Н., Илюшина К. В., Фалалеев А. В. // Вестник ВГУ. Серия: химия, биология, фармация, 2016, № 1, с. 35-42.

11. Караулов А. Е., Рыбин В. Г., Куклев Д. В., Акулин В. Н. // Химия природных соединений, 2004, № 3, c. $189-192$.

12. Mudiyanselage A. Y., Yao H., Viamajala S., Varanasi S., Yamamoto K. // Ind. Eng. Chem. Res., 2015, vol. 54, № 16, p. 4060.

13. Palanisamy A., Rao B. S., Mehazabeen S. // J. Polym. Environ., 2011, vol. 19, № 3, p. 698.

14. Wang X., Wang T., Wang X. // J. Am. Oil Chem. Soc., 2012, vol. 89, № 7, p. 1305.

15. Tufvesson P., Annerling A., Hatti-Kaul R., Adlercreutz D. // Biotech. Bioeng., 2007, vol. 97, № 3, p. 447.

16. Thabuis C., Tissot-Favre D., Bezelgues J.-B., Martin J.-Ch., Cruz-Hernandez C., Dionisi F., Destaillats F. // J. Chromatogr. A, 2008, vol. 1202, № 2, p. 216. 


\title{
INVERSE EMULSIONS STABILIZED BY MONOETHANOLAMIDES OF FATTY ACIDS OF SUNFLOWER OIL
}

\author{
(C) 2017 X. V. Ilyushina, A. S. Shestakov, M. A. Kuzminova, A. V. Falaleev \\ Voronezh State University, 1 Universitetskaya sq., 394018 Voronezh, Russia \\ e-mail: ilyushina.ksyu@yandex.ru
}

Received 14.09.2017

\begin{abstract}
The purpose of the study was to develop methods used to synthesise monoethanolamides of fatty acids of sunflower oil, to analyse the obtained surfactants, to obtain reverse emulsions based on diesel fuel and sunflower oil and to study their stability.

The monoethanolamides of fatty acids of sunflower oil were obtained. The method for production is characterized by the application of sodium aminoethylate as a catalyst and the separation of the target product by means of centrifugation. Three fractions are formed by centrifugation: water, white solids, and a yellow liquid phase. According to HPGS-MS data, the white phase contains the monoethanolamides of all fatty acids, while the yellow phase does not contain the monoethanolamides of saturated fatty acids. The fraction containing the monoethanolamides of unsaturated fatty acids was used as an emulsifier.

Diesel fuel, sunflower oil, and water were used to obtain emulsions. The type of emulsion depends on the method of production. Ultrasonic irradiation is used to obtain direct emulsion, while mechanical agitation leads to the formation of the reverse emulsion. In each case, the type of emulsion was determined by the methods of dilution, the measurement of electrical conductivity, and optical microscopy.

The nature of the emulsion destruction depends on the properties of the non-polar phase. The destruction of the diesel fuel based-inverse emulsion includes two stages. The first stage involves the separation of a small volume of non-polar phase. The separation time depends on the volume of the hydrocarbon phase and the concentration of the emulsifier. The second stage lasts a few weeks and involves the destruction of all the emulsion. The system of sunflower oil-water formation is characterised by the formation of the aqueous phase and the emulsion immediately after mixing. The volume of the emulsion directly depends on the volume of hydrocarbon phase. The emulsion is destroyed within three days. The greatest stability is observed with 3\% (wt.) emulsifier.

Thus, the fraction of monoethanolamides of unsaturated fatty acids of sunflower oil was obtained and it was used together with diesel fuel and sunflower oil to produce inverse emulsions. The study revealed the dependence of the emulsion type on the production method, the nature of the inverse emulsion destruction, the dependence of their stability on the volume of the hydrocarbon phase and the concentration of the emulsifier.
\end{abstract}

Keywords: monoethanolamides, fatty acids, sunflower oil, inverse emulsions, emulsifiers.

\section{REFERENCES}

1. Lange K. R. Surfactants: A Practical Handbook. Hanser Publishers, Munich, 1999.

2. Maag H. J. Am. Oil. Chem. Soc., 1984, vol. 61, no. 2, p. 259. DOI: $10.1007 / \mathrm{BF} 02678778$

3. Sherman Ph. Emulsion Science. Academic Press. London and New York, 1968.

4. Lauermann H. Patent GDR, no. 209190, 1984.

5. Chebaksarova L. V., Khudoleeva E. S., Gurbanova L. V. Patent RF, no. 24516666, 2012.

6. Karpeeva I. V., Zorina, A. V., Shikhaliev Kh. S. Proceedings of Voronezh State University. Series: Chemistry. Biology. Pharmacy, 2013, no. 2, pp. 39-41. Available at: http://www.vestnik.vsu.ru/pdf/chembio/2013/02/2013-0207.pdf (in Russian)
7. Kolancilar H. J. Amer. Oil. Chem. Soc., 2004, vol. 81, no. 6, p. 597. DOI: 10.1007/s11746-006-0947-y

8. Dzylkefly D. J. Oil Palm Res., 1997, vol. 9, no. 2, p. 61.

9. Wang X., Han Z., Chen Y., Jin Q., Wang. X. J. Am. Oil. Chem. Soc., 2016, vol. 93, no. 1, p. 125. DOI: 10.1007/ s11746-015-2749-6

10. Chernykh E. I., Shestakov A. S., Poyarkova T. N., Ilyushina X. V., Falaleev A. V. Proceedings of Voronezh State University. Series: Chemistry. Biology. Pharmacy, 2016, no. 1, pp. 35-42. Available at: http://www.vestnik. vsu.ru/pdf/chembio/2016/01/2016-01-07.pdf (in Russian)

11. Karaulov A. E., Rybin V. G., Kuklev D. V., Akulin V. N. Chemistry of Natural Compounds, 2004, vol. 40, no. 3, p. 222. DOI: 10.1023/B:CONC.0000039128.78645.a8 
12. Mudiyanselage A. Y., Yao H., Viamajala S., Varanasi S., Yamamoto K. Ind. Eng. Chem. Res., 2015, vol. 54, no. 16, p. 4060. DOI: $10.1021 /$ ie $503980 \mathrm{~g}$

13. Palanisamy A., Rao B. S., Mehazabeen S. J. Polym. Environ., 2011, vol. 19, no. 3, p. 698. DOI: 10.1007/s10924011-0316-2

14. Wang X., Wang T., Wang X. J. Am. Oil Chem. Soc., 2012, vol. 89 , no. 7 , p. 1305 . DOI: $10.1007 / \mathrm{s} 11746-012-$ $2017-y$
15. Tufvesson P., Annerling A., Hatti-Kaul R., Adlercreutz D. Biotech. Bioeng., 2007, vol. 97, no. 3, p. 447. DOI: 10.1002/bit.21258

16. Thabuis C., Tissot-Favre D., Bezelgues J.-B., Martin J.-Ch., Cruz-Hernandez C., Dionisi F., Destaillats F. $J$. Chromatogr. A, 2008, vol. 1202, no. 2, p. 216. DOI: 10.1016/ j.chroma.2008.07.008
Илюшина Ксения Валерьевна - студентка кафедры высокомолекулярных соединений и коллоидной химии, Воронежский государственный университет; e-mail: ilyushina.ksyu@yandex.ru

Шестаков Александр Станиславович - д. х. н., заведующий кафедрой высокомолекулярных соединений и коллоидной химии, Воронежский государственный университет; e-mail: schas@vmail.ru

Кузьминова Мария Александровна - студентка кафедры высокомолекулярных соединений и коллоидной химии, Воронежский государственный университет; e-mail:kuzminova@chem.vsu.ru

Фалалеев Александр Владимирович - к. х. н., с. н. с. кафедры органической химии, Воронежский государственный университет; e-mail: noodls@live.com
Ilyushina Xenia $V$. - the student of High Molecular Compounds and Colloid Chemistry Department, Voronezh State University; e-mail: ilyushina.ksyu@yandex.ru

Shestakov Alexander S. - Dr. Sci. (Chem.), the Head of High Molecular Compounds and Colloid Chemistry Department, Voronezh State University; e-mail: schas@ vmail.ru

Kuzminova Maria A. - the student of High Molecular Compounds and Colloid Chemistry Department, Voronezh State University; e-mail: kuzminova@chem.vsu.ru

Falaleev Alexander V. - Cand. Sci. (Chem.), Senior Researcher of Organic Chemistry Department, Voronezh State University; e-mail: noodls@live.com 